PressAcademia Procedia

4th Global Business Research Congress, May 24-25, 2018, Istanbul, Turkey.

\title{
USING ARTIFICIAL NEURAL NETWORK AND A STATISTICAL METHOD FOR THE ESTIMATION OF EURO/TURKISH LIRA EXCHANGE RATE
}

\author{
DOI: 10.17261/Pressacademia.2018.926 \\ PAP- V.7-2018(79)-p.414-417
}

\section{Oktay Tas ${ }^{1}$, Emir Yakak ${ }^{2}$, Umut Ugurlu ${ }^{3}$}

${ }^{1}$ Istanbul Technical University, Management Engineering Deparment, Besiktas, Istanbul, Turkey. oktay.tas@itu.edu.tr, ORCID: 0000-0002-7570-549X

${ }^{2}$ Istanbul Technical University, Management Engineering Deparment, Besiktas, Istanbul, Turkey. yakak16@itu.edu.tr, ORCID: 0000-0002-0476-0280

${ }^{3}$ Istanbul Technical University, Management Engineering Deparment, Besiktas, Istanbul, Turkey. umut.ugurlu@itu.edu.tr, ORCID: 0000-0002-6183-969X

To cite this document

Tas, O., Yaka, E., Ugurlu, U. (2018). Using artificial neural network and a statistical method for the estimation of Euro/Turkish Lira exchange rate. PressAcademia Procedia (PAP), V.7, p.414-417.

Permemant link to this document: $h$ ttp://doi.org/10.17261/Pressacademia.2018.926

Copyright: Published by PressAcademia and limited licenced re-use rights only.

\begin{abstract}
Purpose- The aim of this study is to estimate the movement of the Euro/Turkish lira currency with a statistical method and artificial neural networks methods and to compare the performance of these two methods.

Methodology- In the study, two different forecasting methods were used to estimate the dollar exchange rate. In both models, the Euro/Turkish lira daily rate for the last 10 years was used and the daily dollar rate for the last 1 year was estimated.

Findings- The mean absolute errors found by artificial neural networks method are about $2 \%$ less than those found by the statistical method. Since estimates are made using the "rolling window" method for each of the 365 days, it can be said that the results obtained are "robust". Conclusion- It has been observed that the Artificial Neural Networks model yields more successful results than the statistical model, although both models used in the research can forecast the dollar exchange rate with a certain success. In future studies it may be possible to increase the estimation performance by adding the exogenous variables to the model.
\end{abstract}

Keywords: Exchange rate, artificial neural networks, regression, time series forecast, euro.

JEL Codes: G17, F31, C45

\section{EURO/TL KURU TAHMININDE ISTATISTIK VE YAPAY SINIR AĞLARI KULLANIMI}

ÖZET

Amaç- Bu çalışmanın amacı Euro/Türk lirası kurunun hareketinin istatistik ve yapay sinir ağları yöntemleri ile tahmin edilmesidir.

Yöntem- Çalışmada iki farklı tahmin yöntemi ile Euro/Türk lirası kuru tahmini yapılmıştır. Girdi olarak her iki modelde de son 10 yılın Euro/Türk lirası günlük kuru kullanılmış ve son 1 yılın günlük dolar kuru tahmin edilmiştir.

Bulgular- Yapay sinir ağları yöntemi ile bulunan ortalama mutlak hatalar istatistik yöntemi ile bulunanların yaklaşık \%2'si kadar daha azdır. Tahminler 365 günün her biri için "rolling window" yöntemi kullanılarak yapıldığından, elde edilen sonuçların "robust" olduğu söylenebilir. Sonuç- Araştırmada kullanılan her iki modelin de belirli bir başarı ile Dolar kurunu tahmin tahmin edebildikleri ancak Yapay Sinir Ağları modelinin, istatistik modeline kıyasla daha başarılı sonuçlar verdiği gözlemlenmiştir. Bundan sonraki çalışmalarda dışsal değişkenlerin de modele eklenmesi ile tahmin performansının arttırılabilmesi mümkün olabilir.

Anahtar Kelimeler: Döviz kuru, yapay sinir ağlari, regresyon, zaman serisi tahmini, avro. JEL Kodları: G17, F31, C45 


\section{GíRiş}

Zaman serileri analizinde kullanılan birçok yöntem vardır. Box-Jenkins yöntemi, doğrusal zaman serilerinin analizinde en bilinen ve en çok kullanılan metotlardan biridir. Doğrusal ve durağan süreçlerde ya da durağan olmayan fakat çeşitli istatistiksel yöntemlerle durağanlaştırılabilen serilerde Box-Jenkins yöntemi başarıyla uygulanabilir. Ancak birçok zaman serisi doğrusal ilişkinin yanı sıra doğrusal olmayan ilişki de içerir. Doğrusal olamayan bu ilişkiyi modelleyebilecek farklı yöntemlere gereksinim duyulmaktadır. Yapısında bulunan aktivasyon fonksiyonun özelliğine bağlı olarak hem doğrusal hem de doğrusal olmayan ilişkileri modelleyebilen yapay sinir ağları (YSA) son yıllarda zaman serilerinin analizinde kullanılan alternatif yöntemlerden biri haline gelmiştir.

İnsan beyninin öğrenme kapasitesini taklit eden bir mimariye sahip olan yapay sinir ağları modeli bilgisayar üzerine kurulmuştur. Yapay sinir ağının işleme elemanları insan beyninin iç işlevlerini yerine getiren nöronların biyolojik yapısına benzer. Birbirine bağı birçok temel doğrusal ya da doğrusal olmayan eleman çoklu katmanlarda paralel olarak işlem yaparlar. Bazı çalışmalarda yapay sinir ağlarının veri desenlerini öğrenmede kısıtlamaları olduğu belirtilmektedir. Yapay sinir ağları seçkin öğrenme yeteneğini sunmakla birlikte karmaşık veri nedeni ile tutarlı olmayan ve tahmin edilemeyen bir performans gösterebilmektedir (Gallant, 1993). Buna ek olarak veri bazen o kadar hacimli olmaktadır ki öğrenme desenleri oluşmayabilmektedir. Sürekli veri ve büyük çaptaki kayıtların varlığı nedeni ile gereksiz özelliklerin ayıklanması ve verinin boyutlarının azaltılması algoritmanın işlem süresini kısaltmakta ve daha genellenebilir sonuçlar verebilmektedir (Dash ve Liu, 1997).

Son dönemlerde bu konularda yapılan çalışmalar, insanların bilgi süreçlerinin yapısal ve operasyonel prensiplerini taklit etmeye dayanan veri madenciliği sistemlerinin geliştirilmesine ağırlık vermiştir. Bu araştırmalar sonucu geliştirilen yapay sinir ağları adını, zeka gerektiren sayısız işlemleri yerine getirip sentezleyebilen insan beynindeki hücrelerden almıştır. Bu çalışmada günlük bazda döviz kuru (Euro/TL) verileri kullanılarak farklı ARIMA ve yapay sinir ağı modelleri oluşturulmuş ve her iki veri seti için en iyi sonuçları veren modeller seçilerek iki tekniğin karşılaştırılması için kullanılmıştır.

\subsection{Yapay Sınır Ağları}

Yapay sinir ağları, biyolojik sinir ağlarından esinlenilerek ortaya çıkarılan ve biyolojik sinir ağlarına benzer bazı performans özellikleri içeren bir bilgi işleme sistemidir (Fausett, 1994). Basit bir şekilde insan beyninin çalışma şeklini taklit eden YSA'lar veriden öğrenebilme, genelleme yapabilme, sınırsız sayıda değişkenle çalışabilme vb. birçok önemli özelliğe sahiptir. YSA'nın çalışmasına esas teşkil eden en küçük birimler yapay sinir hücresi ya da işlem elemanı olarak isimlendirilir. En basit yapay sinir hücresi Şekil 1 de de görüleceği üzere girdiler, ağırlıklar, birleştirme fonksiyonu, aktivasyon fonksiyonu ve çıkış olmak üzere 5 ana bileşenden oluşmaktadır.

Girdiler ( $n \times x, x \ldots \times 12$ ), diğer hücrelerden ya da dış ortamlardan hücreye giren bilgilerdir. Bunlar ağın öğrenmesi istenen örnekler tarafından belirlenir. Ağırıklar $\left(w_{1}, w_{2}, \ldots, w_{n}\right)$, girdi kümesi veya kendinden önceki bir tabakadaki başka bir işlem elemanının bu işlem elemanı üzerindeki etkisini ifade eden de- ğerlerdir. Her bir girdi, o girdiyi işlem elemanına bağlayan ağırık değeriyle çarpılarak, toplam fonksiyonu aracılığıyla birleştirilir. Toplam fonksiyonu sonucunda elde edilen değer doğrusal ya da doğrusal olmayan türevlenebilir bir transfer fonksiyonundan geçirilerek işlem elemanının çıktısı hesaplanır

Yapay sinir ağlarında çok çeşitli ağ yapıları ve modelleri vardır. Yapay sinir ağı, bir dizi sinir hücresinin ileri sürümlü ve geri beslemeli bağlantı şekilleri ile birbirine bağlanmasından oluşur. Günümüzde, belirli amaçlarla ve değişik alanlarda kullanılmaya uygun birçok yapay sinir ağı modeli (Perceptron, Adaline, MLP, LVQ, Hopfield, Recurrent, SOM, ART vb.) geliştirilmiştir.

\subsection{ARIMA Modelleri}

ARIMA modelleri, durağan olmayan ancak fark alma işlemiyle durağan hale dönüştürülmüş serilere uygulanan modellerdir. Durağan olmayan ancak fark alma işlemiyle durağan hale dönüştürülmüş serilere uygulanan modellere "durağan olmayan doğrusal stokastik modeller" denir. Bu modeller d dereceden farkı alınmış serilere uygulanan, değişkenin t dönemindeki değerinin belirli sayıdaki geri dönem değerleri ile aynı dönemdeki hata teriminin doğrusal bir fonksiyonu olarak ifade edildiği AR ve değişkenin t dönemindeki değerinin aynı dönemdeki hata terimi ve belirli sayıda geri dönem hata terimlerinin doğrusal fonksiyonu olarak ifade edildiği MA modellerinin birer birleşimidir. Modellerin genel gösterimi ARIMA ( $p, d, q)$ şeklindedir. Burada $p$ ve q sırasıyla Otoregresif (AR) Modelin ve Hareketli Ortalama (MA) Modelinin derecesi, $d$ ise fark alma derecesidir.

\section{LITERATÜR INCELEMESI}

Yapay sinir ağlarının döviz kuru tahmininde kullanılmasına ilişkin literatürde birçok çalışma mevcuttur. Weigend ve diğerleri Alman Markı ile Amerikan Doları arasındaki çapraz kur değerini yapay sinir ağları ve rassal yürüyüş modeli ile tahmin etmişler ve yapay sinir ağlarının rassal yürüyüş modelinden daha iyi sonuçlar verdiğini göstermişlerdir (Weigend vd., 1992). Kuan ve Liu Amerikan Dolarına karşı beş değişik çapraz kuru (İngiliz Sterlini, Kanada Doları, Alman Markı, Japon Yeni, İsviçre Frangı) ileri ve geri beslemeli yapay sinir ağları kullanarak tahmin etmişlerdir (Kuan ve Liu, 1995). Avusturya Dolarına ilişkin altı farklı çapraz kurun ARIMA ve yapay sinir ağları modelleri kullanılarak tahmin edildiği bir çalışma da Kamruzzaman ve Sarker (2003) tarafından yapılmıştır. Bu çalışma sonucunda Kamruzzaman ve Sarker (2003), yapay sinir ağları ile yapılan tahminlerin ARIMA modeli ile yapılan tahminlerden daha iyi sonuç verdi- ğini tespit etmişlerdir. ARIMA ve YSA modellerinin döviz kuru tahminine uygulandığı diğer bir çalışma ise yine yapay sinir ağlarının daha iyi netice verdiği görülmüştür (Wu, 1995). Hann ve Steurer (1996) Amerikan Doları ve Alman Markının çapraz kur tahmininde doğrusal modeller ile yapay sinir ağlarını karşılaştırmışlar; aylık verilerle yapılan uygulamada çok belirgin fark görülmese de haftalık veriler kullanılarak yapılan uygulamada YSA modellerinin doğrusal modellere göre çok daha iyi sonuçlar verdiğini belirtmişlerdir (Hann ve Steurer, 1996). Zhang ve Hu giriş nöron sayısı ve gizli nöron sayısını değiştirerek farklı YSA modelleri oluşturmuşlar ve değişik büyüklükteki veri setlerini bu modellere uygulayarak, farklı yapıdaki ağların ve örnek büyüklüğünün tahmin performansı üzerindeki etkilerini incelemişlerdir (Zhang ve Hu, 1998). Ayrıca, yapay sinir ağlarının zaman serilerinin tahmininde kullanıldığı çalışmalara ilişkin geniş bir derleme Zhang vd tarafından yapılmıştır (Zhang vd., 1998). 


\section{VERI VE YÖNTEM}

Bu çalışmada Euro kurunun yapay sinir ağları modeli ve ARIMA modeli kullanılmıştır. Yapay sinir ağları modelinin ve ARIMA modelinin geliştirilmesinde MATLAB R2017B yazılımından yararlanılmıştır. Günlük bazda döviz kuru (Euro/TL) verileri kullanılmıştır.

\section{BULGULAR VE TARTIŞMA}

Yapay sinir ağları yöntemi ile bulunan ortalama mutlak hatalar istatistik yöntemi ile bulunanların yaklaşık \%2'si kadar daha azdır. Tahminler 365 günün her biri için "rolling window" yöntemi kullanılarak yapıldığından, elde edilen sonuçların "robust" olduğu söylenebilir. Şekil 2'de veri setinin belirli bir kısmı için gerçek ve YSA tahmin değerleri gösterilmektedir.

\section{Şekil 1: Euro/TL Döviz Kuru YSA Tahmini}

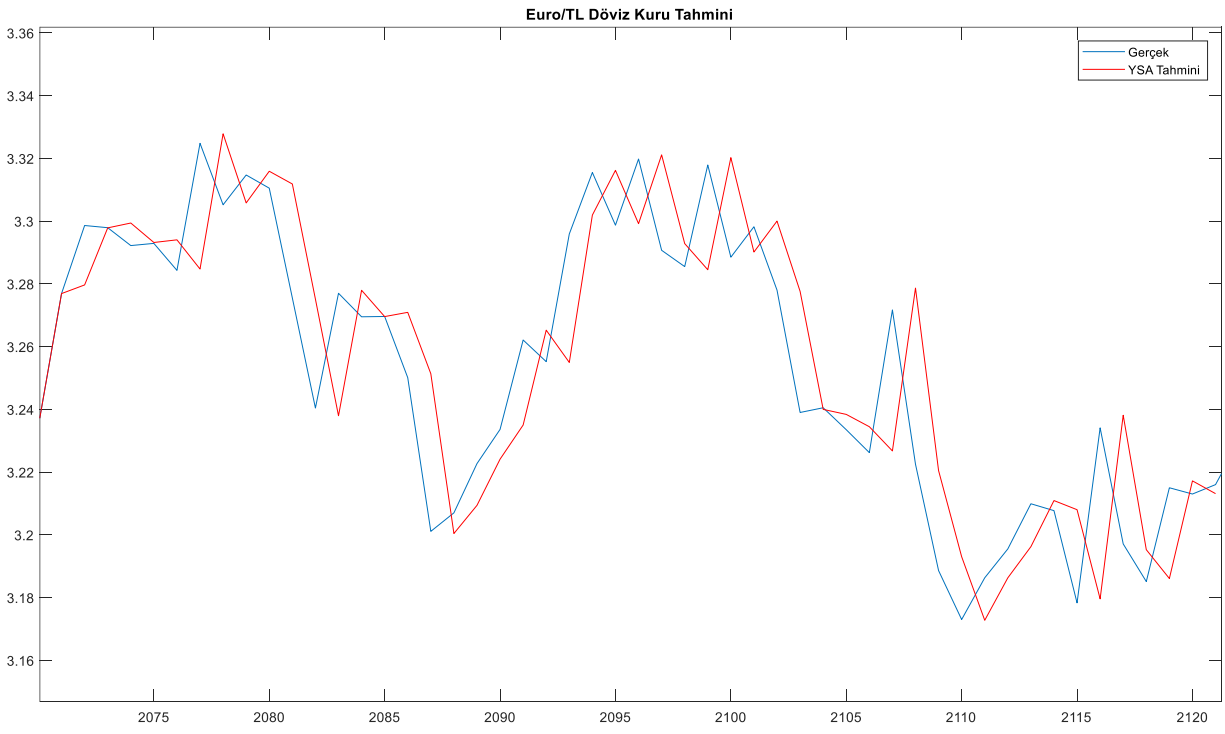

Şekil 2'de de veri setinin aynı kısmı için ARIMA tahmini görülmektedir.

\section{Şekil 2: Euro/TL Döviz Kuru ARIMA Tahmini}

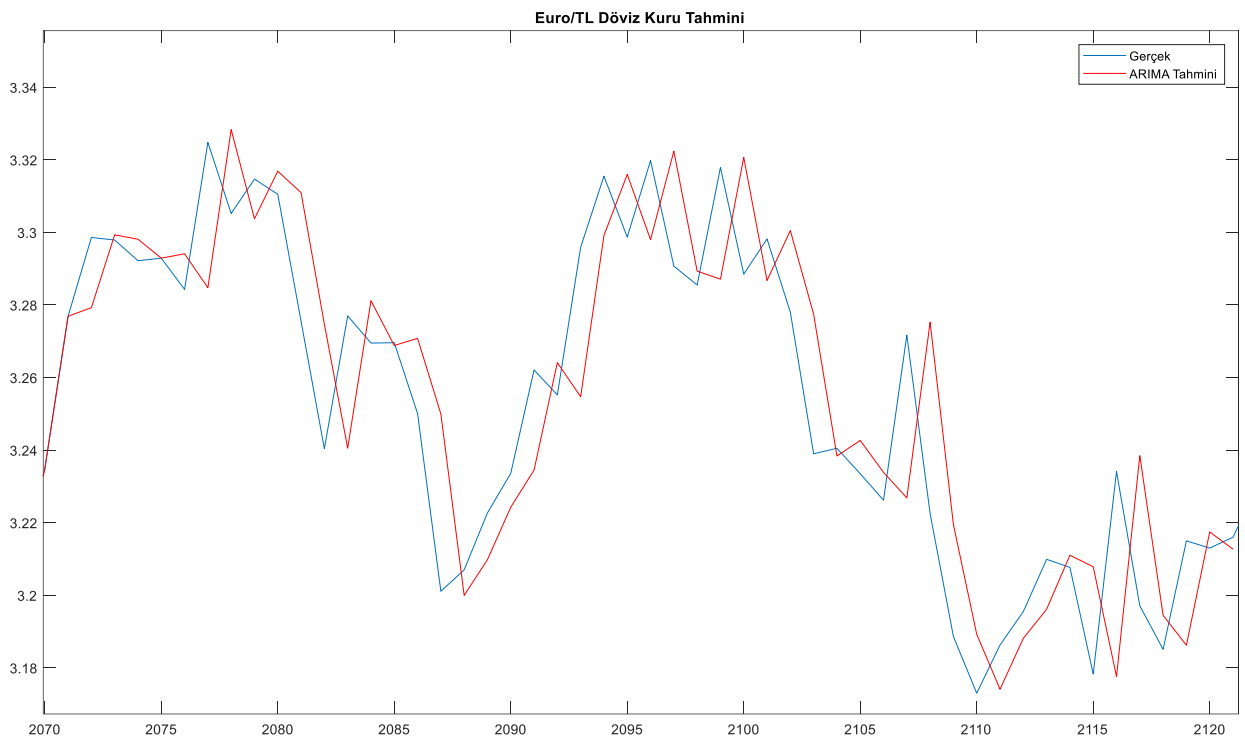




\section{SONUÇ}

Çalışmada kullanılan veriler, Ekim 1997 ile Ekim 2017 arasındaki günlük döviz kuru (Euro/TL) değerleridir. Yapay Sinir ağı modellerinde verinin \%85'i eğitim \%15'i ise doğrulama verisi olarak ayrılmıştır. Bu çalışmada yapay sinir ağları modellerinin oluşturulması için Matlab (ver. 2017b) programı kullanılarak bir yazılım geliştirilmiştir. Çalışma kapsamında oluşturulan tüm Yapay Sinir Ağı modelleri giriş katmanı, çıkış katmanı ve 1 adet gizli katmandan oluşan 3 katmanlı bir mimariye sahiptir. Gerçekleştirilen yazılım sayesinde giriş nöron sayısı ve gizli katmanda kullanılan nöron sayıları 2 den 12' ye kadar değiştirilerek 100 farklı yapay sinir ağı modeli elde edilmiştir. Veriler yapay sinir ağı ile oluşturulan ağlara girilmeden önce ağın yapısına uygun hale getirilerek; gerekli giriş ve çıkış vektörleri oluşturulmuştur. Eğitim verileri ağa sunularak ağın öğrenme işlemi gerçekleştirilmiş bu yüz model içerisinden test verileri için en küçük hata kareleri ortalaması (MAE) değerini veren yapay sinir ağı modeli seçilmiştir. Veri setinin durağanlığı incelenmiş ve durağanlık testi sonuçlarına göre durağan olmayan seriler fark alma yöntemiyle durağan hale getirilmiştir.

Günlük veriler için sabit terim içermeyen ARIMA $(2,0,0)$ modelinin kullanılması uygun görülmüştür. ARIMA ve YSA modelleri MAE performans ölçülerine göre karşılaştııılığında birbirine yakın sonuçlar vermiştir. Veri setinin yukarıda grafiği verilen kısmı için MAE değerlerine bakıldığında ARIMA için (0.0202), YSA için (0.0198) değerine ulaşılmışır.

Bu sonuçlar daha önce yapılmış benzer çalışmalarla paralellik sergilemekte ve eğitimde kullanılan veri sayısı artıkça yapay sinir ağlarının daha iyi sonuç verdiğini göstermedir. Sonuç olarak uygun ağ yapısı ve yeterli sayıda veri kullanıldığında, finansal verilerin tahmininde yapay sinir ağları istatistiksel yöntemlere alternatif bir yöntem olarak kullanılabilir.

\section{KAYNAKLAR}

Dash, M., Liu, H. (1997). Feature selection for classification. Intelligent data analysis, 1(3), 131-156.

Fausett, L. V. (1994). Fundamentals of neural networks: architectures, algorithms, and applications (Vol. 3). Englewood Cliffs: Prentice-Hall. Gallant, S. I. (1993). Neural network learning and expert systems. MIT press.

Hann, T. H., Steurer, E. (1996). Much ado about nothing? Exchange rate forecasting: neural networks vs. linear models using monthly and weekly data. Neurocomputing, 10(4), 323-339.

Kamruzzaman, J., Sarker, R. A. (2003). Forecasting of currency exchange rates using ANN: a case study. In Neural Networks and Signal Processing, 2003. Proceedings of the 2003 International Conference on (Vol. 1, pp. 793-797). IEEE.

Kuan, C. M., Liu, T. (1995). Forecasting exchange rates using feedforward and recurrent neural networks. Journal of applied econometrics, $10(4), 347-364$.

Weigend, A. S., Huberman, B. A., Rumelhart, D. E. (1992). Predicting sunspots and exchange rates with connectionist networks. PRE-33772.

$\mathrm{Wu}$, B. (1995). Model-free forecasting for nonlinear time series (with application to exchange rates). Computational Statistics \& Data Analysis, 19(4), 433-459.

Zhang, G., Hu, M. Y. (1998). Neural network forecasting of the British pound/US dollar exchange rate. Omega, 26(4), 495-506.

Zhang, G., Patuwo, B. E., Hu, M. Y. (1998). Forecasting with artificial neural networks: the state of the art. International journal of forecasting, 14(1), 35-62. 